\title{
Quantitative real-time RT-PCR for determination of vitellogenin mRNA in so-iuy mullet (Mugil soiuy)
}

\author{
Lihui An $\cdot$ Jianying $\mathrm{Hu} \cdot$ Zhaobin Zhang $\cdot$ Min Yang
}

Received: 13 March 2006 /Revised: 15 August 2006 / Accepted: 8 September 2006 / Published online: 28 October 2006

(C) Springer-Verlag 2006

\begin{abstract}
A quantitative real-time reverse transcription polymerase chain reaction (Q- RT-PCR) assay was developed for quantification of vitellogenin (Vtg) mRNA normalized to $\beta$-actin in so-iuy mullet. Vtg mRNA in liver samples of so-iuy mullet was induced after a single injection of E2 $(0.01,0.1,1.0 \mu \mathrm{g} / \mathrm{g}$ body) and a doseresponse relationship was obtained. This method was applied to determine Vtg mRNA in so-iuy mullet collected from Liaodong Bay, Bohai Bay, NanDaiHe, and a control site in north China. Compared to the control, a high level of Vtg mRNA expression was detected in so-iuy mullets collected from NanDaiHe, whereas no obvious difference between Vtg mRNA expression from Liaodong Bay and Bohai Bay was found. Thus, this method is expected to be useful for further studying the potential of Vtg mRNA as a biomarker for assessing estrogenic activity in marine environments using the so-iuy mullet as a bioindicator species.
\end{abstract}

Keywords Biomarker - Endocrine-disrupting chemicals . Quantitative real-time reverse transcription polymerase chain reaction $\cdot$ Vitellogenin $\mathrm{mRNA} \cdot$ So-iuy mullet

\footnotetext{
L. An $\cdot$ J. Hu $(\bowtie) \cdot$ Z. Zhang

College of Environmental Science, Peking University,

Beijing 100871, People's Republic of China

e-mail: hujy@urban.pku.edu.cn

L. An · M. Yang

State Key Laboratory of Environmental Aquatic Chemistry,

Research Center for Eco-Environmental Sciences,

Chinese Academy of Sciences,

Beijing 100085, People's Republic of China
}

\section{Introduction}

Recently, endocrine-disrupting chemicals (EDCs) in aquatic environments have been proven to be responsible for adverse effects in the development of reproductive systems in humans and wildlife [1-3]. To investigate the possible endocrine disruption of xenobiotics in wildlife, biomarkers including plasma steroid concentrations, induction of vitellogenins (Vtgs) or their mRNAs, and alteration of secondary sex characteristics are usually used.

Vitellogenin (Vtg) is the egg yolk precursor protein synthesized in the liver of oviparous female fish, but not in males. However, male fish can synthesize Vtg with estrogen exposure, making it a very specific marker of estrogen exposure in males [4]. A variety of techniques have been applied to determine Vtg induction in fish. Vtg protein levels have been measured by enzyme-linked immunosorbent assay (ELISA) [5] and immunohistochemistry (RIA) [6]. On the other hand, the analysis of Vtg mRNA in liver has been used as a promising approach owing to its high sensitivity and shorter response time compared to the appearance of the protein in blood [7, 8]. Recently, methods based on quantitative reverse transcription polymerase chain reaction (RT-PCR) for determining Vtg gene expression in Chinese sturgeon (Acipenser sinensis Gray) [9] and striped sea bream [10] have been established.

Mullet species (Mugilidae family) are detritivore pelagic fishes distributed worldwide in seas, rivers, and lakes of all regions except for the Arctic and Antarctic Oceans. Mullets are very tolerant and their widespread distribution makes them an important bioindicator species especially in coastal environments. Of about 70 mullet species, so-iuy mullet (Mugil soiuy) is very common in China, Peter the Great Bay (Russia and Korea), and Europe. Recently, an ELISA method for determining Vtg protein of golden grey mullet and a RT- 
PCR method for the analysis of Vtg mRNA of striped mullet have been developed $[11,12]$; however, no method has been reported for determining so-iuy mullet-specific Vtg.

The Bo Sea, which is surrounded by some large cities such as Beijing, Tianjin, and Shenyang, is located in the northeast of China. Large amounts of wastewater are released from these cities and discharged into the Bo Sea. In recent years, the Bo Sea has become seriously polluted according to the Bulletin of Marine Environments of China (http://www.soa. gov.cn/hygb). Nevertheless, little data about the activity of EDCs in the Bo Sea have been reported until now.

A sensitive and reliable quantitative real-time RT-PCR (Q-RT-PCR) for the quantitative determination of hepatic Vtg transcript level in so-iuy mullet was therefore developed and then applied to monitor the Vtg mRNA expressions of wild so-iuy mullets from the Bo Sea. To the best of our knowledge, this is the first description of a methodology for quantitative analysis of Vtg mRNA in soiuy mullet and the first instance where its Vtg mRNA has been detected in a marine environment using the so-iuy mullet as a bioindicator species.

\section{Materials and methods}

Vtg mRNA induction in so-iuy mullet with $17 \beta$-estradiol (E2)

Three mature female so-iuy mullets(L30.5 $\pm 1.5 \mathrm{~cm}, \mathrm{~W} 291.4 \pm$ $28.3 \mathrm{~g}$ ) were intraperitoneally injected with $2 \mathrm{mg} / \mathrm{kg} 17 \beta-$ estradiol (98\% purity, Sigma, St. Louis, MO, USA) dissolved in the same volume peanut oil (Sigma, St. Louis, MO, USA), and three mature male so-iuy mullets were injected with peanut oil as negative control. Injections were given three times within 2 weeks. Fish were cultured in a pond (water temperature $23-25^{\circ} \mathrm{C}$, dissolved oxygen content $6-8 \mathrm{mg} / \mathrm{mL}$ ) and were fed with commercial pellets during the induction period. After 2 days from the last injection, the fish were sampled and the liver tissues were frozen quickly in liquid nitrogen for Vtg mRNA expression analysis.

\section{Dose-response in Vtg mRNA with E2 exposure}

Two-month-old Juvenile so-iuy mullets (body weight 4.0 $6.5 \mathrm{~g})$ were purchased from a fishery in Tianjin, China. Twenty-four individuals randomly selected and transferred to four separate tanks ( $n=6$ per tank) were reared at $24 \pm 1^{\circ} \mathrm{C}$ and under a 14:10 light regime in sea water with salinity of 1520\% (GOEE, Co., Beijing) which was renewed every day.

After 2 weeks, three groups $(n=6)$ of juvenile so-iuy mullets received a single intraperitoneal injection of E2 at $0.01,0.1$, or $1.0 \mu \mathrm{g} / \mathrm{g}$ body, and one group received the peanut oil which acted as negative control. Liver samples were collected after 5 days from injection and processed as described above.

Collection of so-iuy mullet from Liaodong Bay, Bohai Bay, and NanDaiHe

A number of so-iuy mullets were collected by purse net fishing (mesh size $20 \mathrm{~mm}$ ) from Liaodong Bay (28.3 \pm $3.0 \mathrm{~cm}, n=22)$, Bohai Bay (19.5 $\pm 1.5 \mathrm{~cm}, n=19)$, and NanDaiHe $(25.5 \pm 2.2 \mathrm{~cm}, n=19)$ as shown in Fig. 1. Some so-iuy mullets $(21.5 \pm 1.3 \mathrm{~cm}, n=21)$ from a clean pond around Bohai Bay (Fig. 1) were used as a control. The liver tissues were stored in liquid nitrogen as quickly as possible, and the sex was determined by observing gonad slices.

RNA isolation and DNase I digestion

Total RNA (about 20-30 mg liver) was isolated by using $0.5 \mathrm{~mL}$ Trizol reagent (Gibco BRL, Life Technologies, Gaithersburg, MA, USA) according to the manufacturer's instructions. To remove the possibility of contamination with genomic DNA, total RNA was digested with $50 \mathrm{U}$ RNAse-free DNAse I (TaKaRa Biotechnology, Dalian, China). Total RNA was purified after DNAse digestion by two chloroform extractions and ethanol precipitation, and dissolved in diethypyrocarbonate-treated distilled water. The purified RNA was measured at 260 and $280 \mathrm{~nm}$ using a spectrophotometer. The $260 \mathrm{~nm}$ reading was used to estimate the concentration of the total RNA recovered from the isolation and DNAse I digestion. The (260/280) nm ratios, as well as a $1.2 \%$ agarose-formaldehyde gel stained with ethidium bromide, were used to verify the quality of the RNA in samples.

Reverse transcription

Reverse transcription (RT) reagents were purchased from Applied Biosystems (Foster City, CA, USA). The purified total RNA $(0.1 \mu \mathrm{g})$ was incubated at $70{ }^{\circ} \mathrm{C}$ for $10 \mathrm{~min}$, then

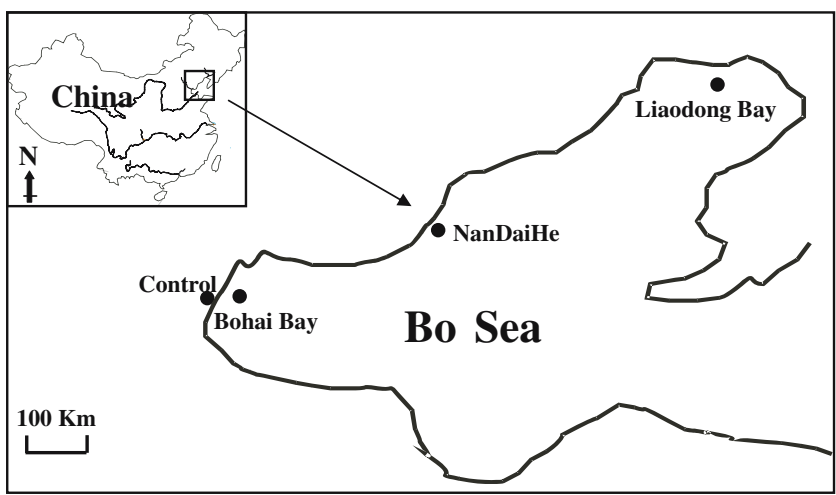

Fig. 1 Collection site of the so-iuy mullet in Liaodong Bay, Bohai Bay, and NanDaiHe in the Bo Sea, and a control site in north China 
mixed briefly and placed in ice immediately. Syntheses of cDNA were carried out in a $5-\mu \mathrm{L}$ reaction mixture containing RNase-free water; $1 \times$ TaqMan RT buffer; $5.5 \mathrm{mM}$ magnesium chloride; $0.5 \mathrm{mM}$ each of dATP, dGTP, dCTP, and dTTP; $2.5 \mu \mathrm{M}$ Oligo(dT) $)_{18} ; 0.4 \mathrm{U} / \mu \mathrm{L}$ RNase inhibitor; and $1.25 \mathrm{U} / \mu \mathrm{L}$ of MultiScribe reverse rranscriptase. The RT reaction was carried out for $5 \mathrm{~min}$ at $25{ }^{\circ} \mathrm{C}, 5 \mathrm{~min}$ at $42{ }^{\circ} \mathrm{C}$, and $45 \mathrm{~min}$ at $50{ }^{\circ} \mathrm{C}$ and then inactivated for $15 \mathrm{~min}$ at $70^{\circ} \mathrm{C}$. A negative control without reverse transcriptase was performed in parallel.

Partial amplification and sequencing of so-iuy mullet Vtg and $\beta$-actin cDNA

To isolate a Vtg cDNA fragment of so-iuy mullet, degenerate primers were designed from a conserved region by alignment of available VTG mRNA sequences from golden grey mullet (Liza aurata, AY129815), largemouth bass (Micropterus salmoides, AF169287), European flounder (Platichthys flesus, AJ416327), and rockfish (Sebastes schlegeli, AY771325) $[13,14]$. Amplification of the so-iuy mullet $\beta$ actin gene was performed according to a similar strategy. The primers of Vtg and $\beta$-actin cDNA are listed in Table 1 .

The cDNA of the E2-treated group was used as a template for the amplification of the Vtg gene. The PCR reactions were performed under the following conditions: $95^{\circ} \mathrm{C}$ for $1 \mathrm{~min}$; followed by 35 cycles at $95^{\circ} \mathrm{C}$ for $30 \mathrm{~s}, 55^{\circ} \mathrm{C}$ for $10 \mathrm{~s}$, and $72{ }^{\circ} \mathrm{C}$ for $30 \mathrm{~s}$; and then $72{ }^{\circ} \mathrm{C}$ for $5 \mathrm{~min}$. After $1.2 \%$ agarose gel electrophoresis, the amplified bands were cut and purified from agarose gel using Wizard $\AA$ PCR Preps DNA Purification System (Promega, Madison, WI, USA). Part of the purified PCR product was sequenced with corresponding PCR primers on an ABI PRISM ${ }^{\mathrm{TM}} 377 \mathrm{XL}$ DNA Sequencer (Applied Biosystems), and the other parts were saved to make a standard curve of real-time PCR.

\section{Q-RT-PCR}

The specific primers for $\mathrm{Vtg}$ and $\beta$-actin were designed from the obtained sequences (Table 1). To prepare a quantification curve, the concentration of the purified PCR product DNA was estimated by the optical density at $260 \mathrm{~nm}\left(\mathrm{OD}_{260}\right)$, and the number of copies per milliliter of standard was calculated according to the process described by Zhang et al. [9]. The purified PCR products were then serially diluted as follows: Vtg at six dilutions from $1 \times 10^{4}$ to $1 \times 10^{9}$ copies $/ \mu \mathrm{L} ; \beta$-actin at six dilutions from $1 \times 10^{5}$ to $1 \times 10^{10}$ copies $/ \mu \mathrm{L}$.

SYBR ${ }^{\circledR}$ Green real-time PCR was performed in MicroAmp ${ }^{\circledR}$ optical 96-well reaction plates with optical caps using an ABI Prism ${ }^{\circledR} 7000$ Sequence Detection System (Applied Biosystems). The PCR assays were carried out under the following conditions: $10 \mu \mathrm{L}$ SYBR ${ }^{\circledR}$ Green PCR master mix (Applied Biosystems), $250 \mathrm{nM}$ each of forward and reverse
Table 1 Polymerase chain reaction (PCR) primers used for amplifying so-iuy mullet vitellogenin (VTG) and $\beta$-actin partial sequences for conventional PCR and for SYBR Green real-time PCR assay (F: upper; R: lower)

\begin{tabular}{|c|c|c|}
\hline & Gene & Primer \\
\hline \multirow[t]{10}{*}{ Degenerate primers } & Vtg & $\mathrm{F}: 5^{\prime}-\mathrm{ACA}(\mathrm{G}, \mathrm{A}, \mathrm{C})(\mathrm{G}, \mathrm{T})$ \\
\hline & & $(\mathrm{A}, \mathrm{G}, \mathrm{T})(\mathrm{A}, \mathrm{G}, \mathrm{T}) \mathrm{CAG}(\mathrm{A}, \mathrm{G}) \mathrm{A}$ \\
\hline & & $(\mathrm{C}, \mathrm{A}, \mathrm{G}) \mathrm{C}(\mathrm{T}, \mathrm{A}) \mathrm{GATCAA}-3^{\prime}$ \\
\hline & & R:5'- GTGC(A,G)(A,G) \\
\hline & & $(\mathrm{A}, \mathrm{T}) \mathrm{ACTC}(\mathrm{T}, \mathrm{G}, \mathrm{C}) \mathrm{T}(\mathrm{G}, \mathrm{C}, \mathrm{A}) \mathrm{T}$ \\
\hline & & $(\mathrm{G}, \mathrm{C}) \mathrm{T}(\mathrm{G}, \mathrm{A}) \mathrm{A}-3^{\prime}$ \\
\hline & $\beta$-actin & $\mathrm{F}: 5^{\prime}-\mathrm{CAGGG}(\mathrm{T} / \mathrm{C}) \mathrm{GT}(\mathrm{G} / \mathrm{C}) \mathrm{AT}$ \\
\hline & & GGT(T/G)GG(T/C/G)AT-3' \\
\hline & & R:5'-(T/G)GTTGGC(T/C)TTG \\
\hline & & GG(G/A)TT(G/C)AG-3' \\
\hline \multirow[t]{8}{*}{ Real-time PCR primers } & Vtg & F:5'-CCCATCAACAACCTGC \\
\hline & & CATAC-3' R:5'-CAAAGA \\
\hline & & AGACCTCCTGAAGAC \\
\hline & & CAT-3' \\
\hline & $\beta$-actin & F:5'-GTGATGAAGCC \\
\hline & & CAGAGCAAGA-3' R:5'- \\
\hline & & TGGTCACAATACCGTG \\
\hline & & CTCAAT-3' \\
\hline
\end{tabular}

primers, and $0.5 \mu \mathrm{L}$ cDNA template were added to a $20-\mu \mathrm{L}$ total reaction volume. The reactants were incubated at $50{ }^{\circ} \mathrm{C}$ for 2 min to activate the uracil N9-glycosylase (in SYBR ${ }^{\circledR}$ Green PCR master mix) and activate the Amplitaq Gold DNA polymerase (in SYBR ${ }^{\circ}$ Green PCR master mix), followed by 40 cycles at $95{ }^{\circ} \mathrm{C}$ for $15 \mathrm{~s}$ and $60^{\circ} \mathrm{C}$ for $60 \mathrm{~s}$. Following the final cycle of the PCR, the reactions were denatured over a $35{ }^{\circ} \mathrm{C}$ temperature gradient at $0.03{ }^{\circ} \mathrm{C} / \mathrm{s}$ from 60 to $95{ }^{\circ} \mathrm{C}$ to determine the quality of $\mathrm{PCR}$ products.

Statistical analyses

The statistical program SPSS (Ver 11.0; Chicago, IL, USA) was used to collect and analyze all data. Independent $t$ test analysis was used to determine whether the results were statistically significant $(p<0.05)$. All data are expressed as the mean \pm standard deviation.

\section{Results}

Partial amplification and sequencing of so-iuy mullet Vtg and $\beta$-actin cDNA

A fragment of Vtg cDNA from so-iuy mullet liver was amplified by PCR using degenerate primers. The resulting fragment was purified and sequenced. A 408-bp sequence corresponding to a 136 amino acid sequence was obtained (Fig. 2). The obtained sequence was confirmed by BLAST 


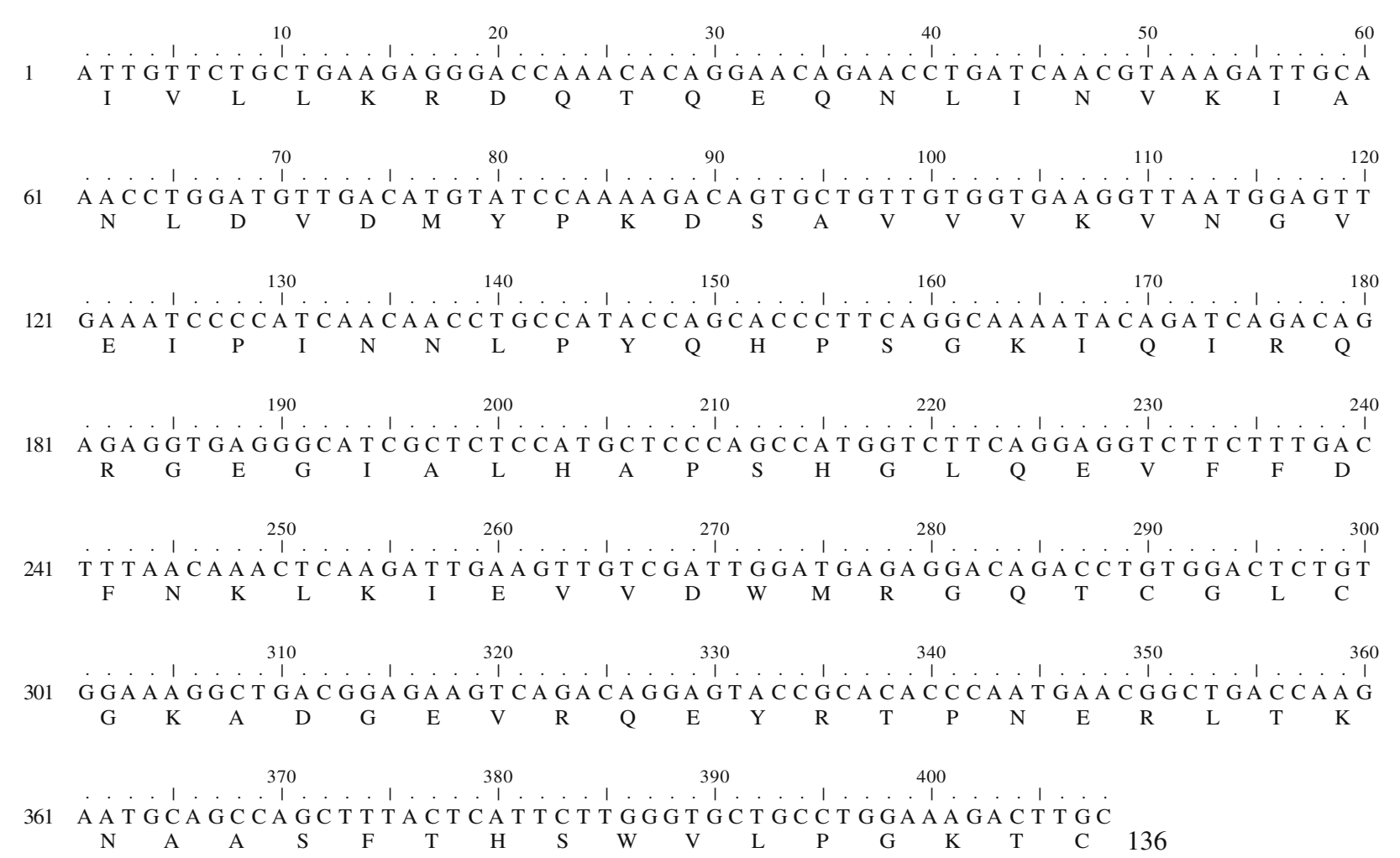

Fig. 2 Partial nucleotide and protein of the so-iuy mullet vitellogenin gene. The numbers above the sequence indicate the nucleotide position, and those on the left and right correspond to the nucleotide and the amino acid residues

(http://www.ncbi.nlm.nih.gov/BLAST/), and the deduced amino acid sequence was aligned with those of golden grey mullet (Liza aurata, AY129815) and largemouth bass (Micropterus salmoides) (AF169287). Based on the identity matrix, the search results showed $94.8 \%, 77.2 \%$, and $57.3 \%$ sequence identities with those of golden grey mullet, largemouth bass, and common carp, respectively (Fig. 3). By a similar strategy, a 203-bp $\beta$-actin fragment corresponding to a 67 amino acid sequence was isolated and sequenced (Fig. 4), and the deduced amino acid sequence showed $98.5 \%, 97.0 \%$, and $95.5 \%$ identities with $\beta$-actin of milkfish (Chanos chanos, DQ202397), common carp (Cyprinus carpio, M 24113), and zebrafish (Danio rerio, AF 057040), respectively.

\section{Q-RT-PCR for Vtg mRNA}

In this study, standard curves for both Vtg and $\beta$-actin were linear over 6 orders of magnitude with the linear correlation $\left(r^{2}>0.99\right)$ between the threshold cycle $\left(C_{t}\right)$ and the number of copies of the target. The specificity of real-time RT-PCR with SYBR Green detection was ascertained by comparing the heat dissociation curves of the amplification products from different samples to those of the standards. The melting temperatures of the 112-bp Vtg amplification and the 69-bp $\beta$-actin amplification were 87.1 and $82.3{ }^{\circ} \mathrm{C}$, respectively. All samples exhibited a melting temperature within $\pm 1{ }^{\circ} \mathrm{C}$ of those of the standards, and no hairpin or dimer was detected.

The Q-RT-PCR method developed above was used to quantify the level of Vtg mRNA in liver samples, which were treated with E2. All samples were reverse transcribed in duplicate. To decrease the error that occurs in the course of RNA isolation and RT, the ratios of Vtg to $\beta$-actin cDNA were used to assess the Vtg gene expression in samples. Vtg mRNA expressions at the doses of $0.01,0.1$, and $1.0 \mu \mathrm{g} \mathrm{E} 2 / \mathrm{g}$ body were all significantly higher than that of control $(0.0012 \pm 0.0006$ copies/copy $\beta$-actin, $p<0.05)$ and a dose-dependent increase in Vtg mRNA was found as shown in Fig. 5.

Quantification of Vtg mRNA in livers of so-iuy mullet from Lliaodong Bay, Bohai Bay, and NanDaiHe

We applied the Q-RT-PCR assay developed in the present study to investigate Vtg mRNA in so-iuy mullets inhabiting Liaodong Bay, Bohai Bay, and NanDaiHe, and the levels of Vtg mRNA are listed in Table 2. It was found that while the Vtg mRNA levels in so-iuy mullets from Liaodong Bay $(0.00073 \pm 0.0012$ copies/copy $\beta$-actin in males and $0.0028 \pm 0.0036$ copies/copy $\beta$-actin in females) and Bohai Bay $(0.0012 \pm 0.0007$ copies/copy $\beta$ actin in females and $0.0011 \pm 0.0014$ copies/copy $\beta$-actin in males) were similar to those collected from the control site 


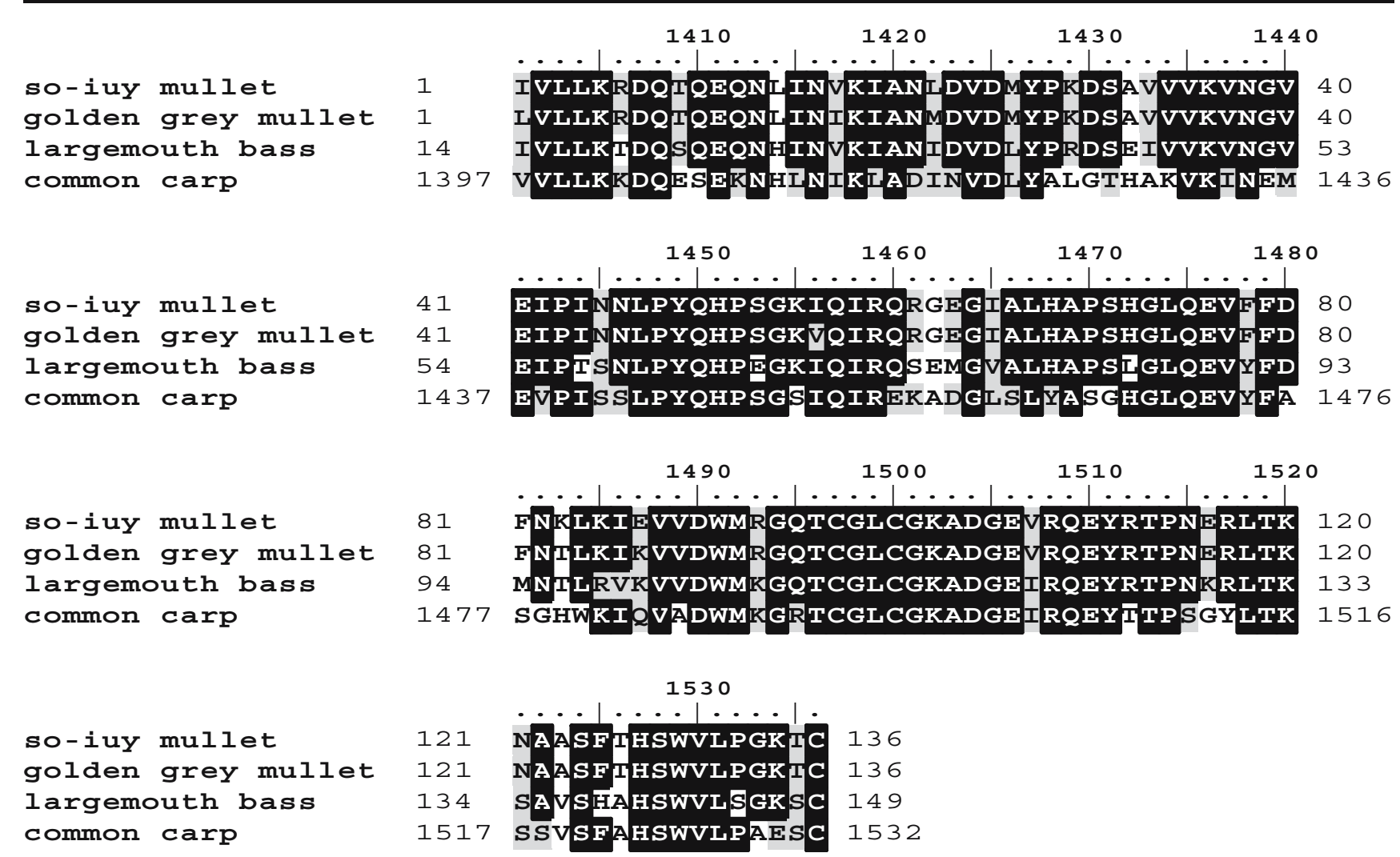

Fig. 3 Comparison of the partial amino acid sequence of so-iuy mullet vitellogenin with those of golden grey mullet, largemouth bass, and common carp. The alignment was generated using the ClustalW alignment

$(0.0011 \pm 0.008$ copies/copy $\beta$-actin in males and $0.0010 \pm$ 0.0008 copies/copy $\beta$-actin in females), the Vtg mRNA levels from NanDaiHe $(0.13 \pm 0.14$ copies/copy $\beta$-actin in males and $0.16 \pm 0.17$ copies/copy $\beta$-actin in females) were higher significantly than those from control site $(p<0.05)$, suggesting that EDCs in NanDaiHe at the sampling date could induce Vtg gene expression in the wild so-iuy mullet populations.

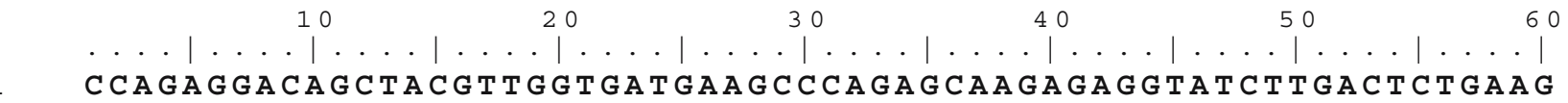

1

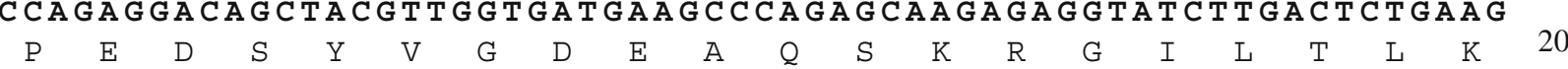

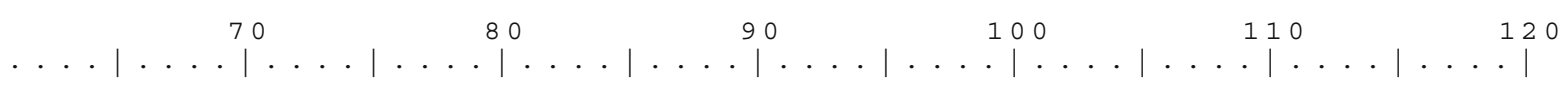

61 TACCCCATTGAGCACGGTATTGTGACCAACTGGGATGACATGGAGAAGATCTGGCATCAC
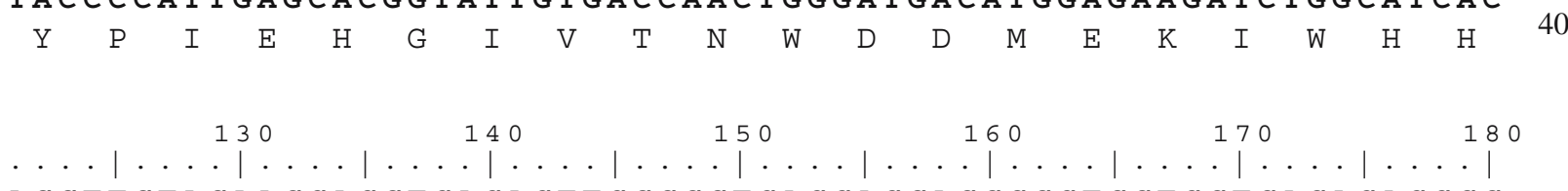

121 A C

$\begin{array}{lllllllllllllllllllll}T & \mathrm{~F} & \mathrm{Y} & \mathrm{N} & \mathrm{E} & \mathrm{L} & \mathrm{R} & \mathrm{V} & \mathrm{A} & \mathrm{P} & \mathrm{E} & \mathrm{E} & \mathrm{H} & \mathrm{P} & \mathrm{V} & \mathrm{L} & \mathrm{L} & \mathrm{T} & \mathrm{E} & \mathrm{A} & 60\end{array}$

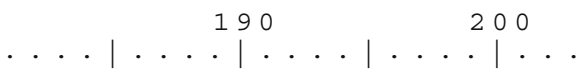

181 C CCCTGAACCCCAAAGCCAACAA

$$
\begin{array}{lllllll}
P & \mathrm{~L} & \mathrm{~N} & \mathrm{P} & \mathrm{K} & \mathrm{A} & \mathrm{N}
\end{array}
$$

Fig. 4 Partial nucleotide and protein of the so-iuy mullet $\beta$-actin gene. The numbers above the sequence indicate the nucleotide position, and those on the left and right correspond to the nucleotide and the amino acid residues 


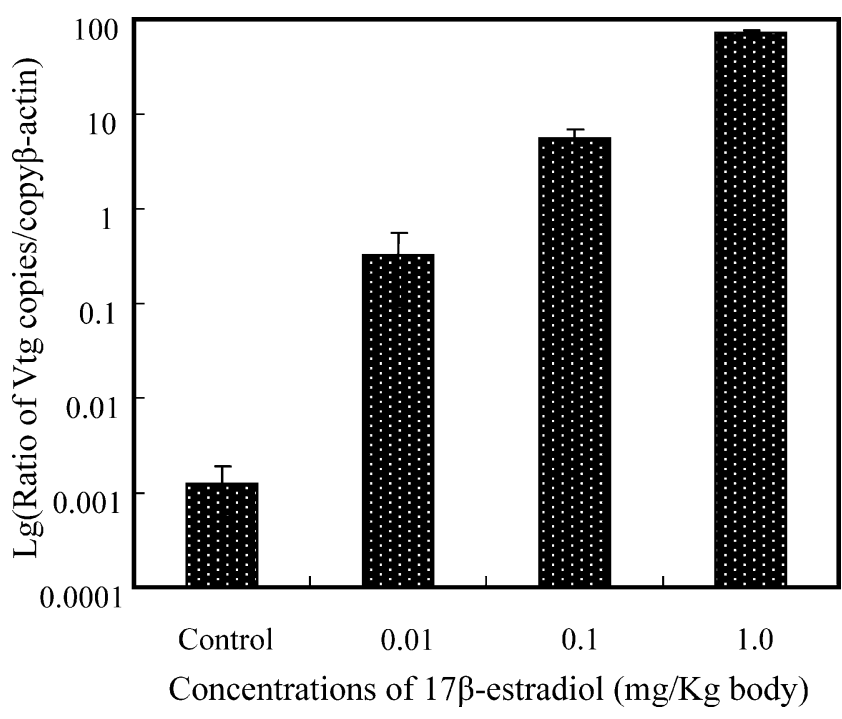

Figure 5 Induction of so-iuy mullet Vtg mRNA by single E2 injection treatment for 5 days. Values are the mean $\pm \mathrm{SD}(n=6)$

\section{Discussion}

Q-RT-PCR is a new method for analyzing gene expression with several advantages such as speed, directness, and accuracy $[15,16]$. Though the obtained Vtg gene sequences of studied organisms are essential, methods based on degenerate primers and RT-PCR could quickly isolate a fragment of target genes, and partial sequences could be obtained in a few days.

In this study, a fragment of so-iuy mullet Vtg cDNA was isolated and sequenced (Fig. 1). The deduced amino acid sequence showed high identity with those of golden grey mullet and Pagrus major (Fig. 2). Using a similar strategy, the sequences of fragment $\beta$-actin of so-iuy mullet were isolated, sequenced, and confirmed (Fig. 3). Primers for RT-PCR were designed based on the partial sequences. In this case, the Q-RT-PCR method for analyzing so-iuy mullet Vtg gene expression was carried out in one week, so this method should be preferred in assessing the presence of environmental estrogens in the marine environment.

Table 2 Quantification of liver VTG mRNA by quantitative real-time PCR in male and female so-iuy mullets collected from Liaodong Bay, NanDaiHe, Bohai Bay, and a control site in north China

\begin{tabular}{lll}
\hline Location & Male & Female \\
\hline Control site & $0.0011 \pm 0.008(n=10)$ & $0.0010 \pm 0.0008(n=11)$ \\
Liaodong Bay & $0.00073 \pm 0.0012(n=14)$ & $0.0028 \pm 0.0036(n=8)$ \\
Bohai Bay & $0.0015 \pm 0.0008(n=6)$ & $0.00132 \pm 0.0005(n=13)$ \\
NanDaiHe & $0.13 \pm 0.14(n=11)$ & $0.16 \pm 0.17(n=8)$ \\
\hline
\end{tabular}

The data were expressed as the ratio of Vtg copies/copy $\beta$-actin. Values are the mean \pm SD
In this study, $\beta$-actin gene was used as the housekeeping gene. It was found that $\beta$-actin copies/ng total RNA has a decreasing trend with increasing E2 dose when injection dose ranged from $0.01(p=0.99)$ to $1.0 \mu \mathrm{g} / \mathrm{g}$ $(p=0.948)$. Because the Vtg mRNA expression after E2 injection even at low dose is obvious, however, such variation of $\beta$-actin copies can be neglected for the evaluation of Vtg mRNA expression. Published reports $[17,18]$ have suggested that the time course for maximum induction of Vtg mRNA ranges from $16 \mathrm{~h}$ to 15 days depending on the species, route of exposure, and doses used. Despite the fact that the optimal time point for mRNA induction may not have been used in the present study, Vtg mRNA expression was induced after single injection for 5 days. In this experiment, even the lowest dose, $0.01 \mu \mathrm{g}$ E2/g body, obviously induced Vtg mRNA expression after single injection, which appears to be more sensitive than juvenile rainbow trout [19].

The wild so-iuy mullets were all out of the reproductive stage, and most so-iuy mullets collected for this study were immature. From the above results, there is background Vtg mRNA expression detected in juvenile and male so-iuy mullet reared in lab or collected from a clean pond. This is similar to the previous reports that tilapia [20] and sheephead minnows [21] have natural variations with low but detectable background levels of Vtg mRNAs in male. Compared to the background, the Vtg mRNA expression level showed no obvious difference in the so-iuy mullet collected from the Liaodong Bay and Bohai Bay, whereas Vtg mRNA expression in so-iuy mullet collected from NanDaiHe was more than 100 times that in Liaodong Bay and Bohai Bay. It should be noted that there was considerable variation in Vtg mRNA expression levels among males or females, which was also found in a previous paper [19]. Such fish-to-fish variability was explained by the differences in the kinetics of induction and clearance of mRNA and the inaccuracy during delivery of the different compounds due to the different sizes of the wild so-iuy mullets [19]. There is a need to determine EDCs in the sampling sites in future, and to determine plasma Vtg protein considering the fact that the Vtg mRNA expression only indicated the potential current exposure for individuals [8].

\section{Conclusion}

This study confirms that the Q-RT-PCR assay developed here would be useful for monitoring Vtg mRNA in so-iuy mullet as well as for the development of an in vivo system for screening estrogenic substances using so-iuy mullet as a sentinel bioindicator in the environment. 
Acknowledgments We are grateful to Kefeng Liu of Tianjin Fisheries Research Institute, Tianjin, China, for providing so-iuy mullet rearing. Financial support from the National Natural Science Foundation of China [20377002 and 40021101] and the National Basic Research Program of China [2007CB407304] is gratefully acknowledged.

\section{References}

1. Solé M, Porte C, Barceló D (2001) Trends Anal Chem 20:518525

2. Thorpe KL, Hutchinson TH, Hetheridge MJ, Scholze M, Sumpter JP, Tyler CR (2001) Environ Sci Technol 35:2476-2481

3. Lomax DP, Roubal WT, Moore JD, Johnson LL (1998) Comp Biochem Physiol B 121:425-436

4. Kime DE, Nash JP, Scott AP (1999) Aquaculture 177:345-352

5. Fenske M, van Aerle R, Brack S, Tyler CR, Segnera H (2001) Comp Biochem Phys C 129:217-232

6. Koya Y, Matsubara T, Ikeuchi T, Adachi S, Yamauchi K (1997) Comp Biochem Physiol A 118:1217-1223

7. vanden Heuvel JP, Tyson FL, Bell DA (1993) Biotechniques $14: 395-398$
8. Hemmer MJ, Bowman CJ, Hemmer BL, Friedman SD, Marcovich D, Kroll KJ, Denslow ND (2002) Aquat Toxicol 58:99-112

9. Zhang ZB, Hu JY, An W, Jin F, An LH, Tao S, Chen JS (2005) Environ Toxicol Chem 24:1944-1950

10. Funkenstein B, Dyman A, Levavi-Sivan B, Tom M (2004) Mar Environ Res 58:659-663

11. Asturiano JF, Romaguera F, Aragon P, Atienza J, Puchades R, Maquieira A (2005) Anal Bioanal Chem 381:1152-1160

12. Canapa A, Barucca M, Celeste A, Olmo E, Regoli F (2002) Mar Environ Res 54:673-677

13. Bowman CJ, Denslow ND (1999) Ecotoxicology 8:399-416

14. Bowman CJ, Kroll KJ, Hemmer MJ, Folmar LC, Denslow ND (2000) Gen Comp Endocrinol 120:300-313

15. Islinger M, Pawlowski S, Hollert H, Volkl A, Braunbeck T (1999) Sci Total Environ 233:109-122

16. Larkin P, Knoebl I, Denslow ND (2003) Comp Biochem Physiol B 136:149-161

17. Lim EH, Ding JL, Lam TJ (1991) Gen Comp Endocrinol 82:206-214

18. Pakdel F, Feon S, Le Gac F, Le Menn F, Volotaire Y (1991) Mol Cell Endocrinol 75:205-212

19. Celius T, Matthews JB, Giesy JP, Zacharewski TR (2000) J Steroid Biochem 75:109-119

20. Lim EH, Ding JL, Lam TJ (1991) Gen Comp Endocrinol 82:206-214

21. Bowman CJ, Kroll KJ, Hemmer MJ, Flomar LC, Denslow ND (2000) Gen Comp Endocrinol 120:300-313 